\title{
FARELO DE ARROZ INTEGRAL EM RAÇÕES PARA LEITÕES DE 43 A 67 DIAS DE IDADE
}

\author{
Thalles Ribeiro Gomes ${ }^{1}$, Luiz EuQuerio de CARVALHO ${ }^{2}$, EdNARDo Rodrigues Freitas ${ }^{2}$, RAFAEL \\ CARlos NEPOMUCENO ${ }^{1}$, Everardo Ayres CORREIA ElLERY ${ }^{3}$, RENNAN HERCUlano RuFino \\ MOREIRA $^{4}$ \\ ${ }^{1}$ Doutorando em Zootecnia da Universidade Federal do Ceará, Fortaleza, CE, Brasil.. Email: thalleszoo@ yahoo.com.br \\ ${ }^{2}$ Professores Doutores da Universidade Federal do Ceará. Fortaleza, CE, Brasil \\ ${ }^{3}$ Pós-graduando em Zootecnia da Universidade Federal do Ceará. Fortaleza, CE, Brasil \\ ${ }^{4}$ Pós-graduando em Zootecnia da Universidade Federal de Lavras. Lavras, MG, Brasil
}

\begin{abstract}
Foram utilizados 64 leitões, fêmeas e machos castrados, de linhagem comercial, com média de 43 dias de idade e com peso inicial médio de $10,73 \pm 1,85 \mathrm{~kg}$, com o objetivo de se avaliar os efeitos da inclusão de farelo de arroz integral (FAI) na ração até 67 dias de idade sobre o desempenho zootécnico, formas de arraçoamento e viabilidade econômica. $\mathrm{O}$ delineamento experimental utilizado foi inteiramente casualizado, em arranjo fatorial 4 x 2, quatro níveis de inclusão de farelo de arroz integral $(0,10,20$ e $30 \%)$ e duas formas de arraçoamento (ração seca e ração úmida), com quatro repetições por

tratamento, sendo a unidade experimental constituída por 2 animais. O consumo diário de ração (CDR), ganho diário de peso (GDP) e a conversão alimentar (CA) não diferiram significativamente $(\mathrm{P}>0,05)$ para os diferentes níveis de inclusão de FAI ou para a forma de arraçoamento. A análise econômica mostrou que a inclusão de $30 \%$ de FAI apresentou a melhor resposta econômica. Concluiu-se que o fornecimento de farelo de arroz integral foi viável até o nível de $30 \%$ de inclusão nas dietas de leitões no período de 43 a 67 dias da fase inicial, independente da forma de arraçoamento.
\end{abstract}

PALAVRAS-CHAVE: Alimento alternativo; análise econômica; desempenho zootécnico; suínos.

\section{RICE BRAN IN DIETS FOR PIGLETS FROM 43 TO 67 DAYS OF AGE}

\section{ABSTRACT}

A total of 64 piglets, castrated male and female, of commercial lineage, weaned at 43 days of age and with average live weight of $10.73 \pm 1.85 \mathrm{~kg}$, were used with the objective of evaluating the effect of the inclusion of different levels of rice bran $(\mathrm{RB})$ in ration up to 67 days of age on productive performance, feeding forms and economic viability. The experimental design was completely randomized in a $4 \times 2$ factorial arrangement, four levels of inclusion of $\mathrm{RB}(0,10,20$ and 30\%) and two feeding forms (dry ration and wet ration), with four replicates per treatment, and the experimental unit consisted of two animals. The daily feed intake (DFI), daily weight gain (DWG) and feed conversion (FC) did not differ significantly $(\mathrm{P}>0.05)$ for the different levels of inclusion of $\mathrm{RB}$ or the feeding forms. The economic analysis showed that the inclusion of $30 \%$ of RB had the best economic response. It was concluded that the supply of rice bran was viable until the level of $30 \%$ of inclusion in diets of piglets in the period from 43 to 67 days of initial phase, regardless of the feeding forms.

KEYWORDS: Alternative feedstuff; bioeconomic analysis; swine; zootechnical performance.

\section{INTRODUÇÃO}

A rentabilidade da atividade suinícola baseia-se principalmente na redução dos custos de produção e maximização da produtividade. A nutrição é um elemento de grande importância em qualquer criação, sobretudo na suinocultura, em que representa cerca de $75 \%$ dos custos de produção. Os principais fatores 
responsáveis pelas elevadas despesas com a alimentação são os preços do milho e do farelo de soja e os custos provenientes da importação desses ingredientes de outras regiões do país e do exterior, em virtude da escassez de grãos no Nordeste, especialmente do milho (RAMOS et al., 2006), gerando uma constante busca de matériasprimas alternativas que possam substituí-los.

O arroz é um dos cereais mais produzidos no mundo, utilizado principalmente na alimentação humana. Comumente, devido a seu custo ser maior que o do milho, apenas os subprodutos de seu beneficiamento (farelo de arroz integral, farelo de arroz desengordurado, quirera e óleo de arroz) são utilizados na alimentação animal, constituindo-se em excelentes fontes de nutrientes (LIMA et al., 2000).

$\mathrm{O}$ farelo de arroz integral (FAI) é obtido após a brunição e polimento do grão de arroz sem casca, representando de $8 \%$ a $11 \%$ do peso total do grão (PARRADO et al., 2006). Ele apresenta aspecto farináceo e fibroso, suave ao tato, e é constituído da camada intermediária entre a casca e o endosperma, gérmen, fragmentos de arroz e pequenas quantidades de casca com granulometria semelhante ao farelo (LAKKAKULA et al., 2004).

Conforme os valores tabelados por ROSTAGNO et al. (2005), o FAI é um alimento energético que apresenta energia digestível, metabolizável e líquida para suínos de 3.179, 3.111 e $2.384 \mathrm{kcal} / \mathrm{kg}$, respectivamente; $89,30 \%$ de matéria seca; $13,24 \%$ de proteína bruta; $14,81 \%$ de gordura; $12,58 \%$ fibra em detergente ácido; $21,30 \%$ fibra em detergente neutro; $0,11 \%$ de cálcio; e $0,32 \%$ de fósforo disponível.

A composição química do FAI pode variar em função do tipo de processamento do arroz, uma vez que não existe uma padronização do método de polimento do grão de arroz durante o seu beneficiamento para o consumo humano. A variedade genética e as condições ambientais nas quais a planta foi cultivada também influenciam a composição química e a distribuição dos componentes químicos do grão de arroz (CARVALHO \& BASSINELO, 2006). Segundo HOFFPAUER (2005), os teores de amido e fibra bruta, em especial, podem variar em função do grau de polimento do arroz e da quantidade de casca incorporada ao farelo de arroz. Outro aspecto importante é que a sua utilização é limitada devido a efeitos anti-nutricionais, sendo o alto teor de fibra, a presença de fitatos e inibidores enzimáticos e a rancidez oxidativa durante o armazenamento os mais citados e que podem prejudicar a digestibilidade dos nutrientes da ração (SELLE et al., 2000; LE GOFF, 2002).

Existem poucas informações com relação ao efeito da inclusão do FAI nas rações de leitões na fase inicial. Assim, são necessários estudos a respeito dessa inclusão com a finalidade de proporcionar alternativas aos suinocultores.
Neste trabalho, o objetivo foi avaliar os efeitos de diferentes níveis de inclusão de farelo de arroz integral em rações para leitões de 43 a 67 dias de idade sobre o desempenho zootécnico e a viabilidade econômica.

\section{MATERIAL E MÉTODOS}

O experimento foi conduzido no Setor de Suinocultura do Departamento de Zootecnia do Centro de Ciências Agrárias da Universidade Federal do Ceará (DZ/CCA/UFC), situado no Campus do Pici, em Fortaleza - CE, localizado a $03^{\circ} 43^{\prime} 02^{\prime \prime}$ latitude e $38^{\circ}$ 32 ' 35" longitude, com altitude de 15,49 metros acima do nível do mar. Foram utilizados 64 leitões fêmeas e machos castrados, de linhagem comercial, provenientes do Setor de Suinocultura/UFC, com média de 43 dias de idade e peso vivo médio de $10,73 \pm 1,85 \mathrm{~kg}$. O experimento teve duração de 24 dias e foi realizado durante a fase inicial II compreendida entre 43 a 67 dias de idade.

$\mathrm{O}$ delineamento experimental foi inteiramente casualizado, em arranjo fatorial $4 \times 2$ (quatro níveis de inclusão de farelo de arroz integral: 0, 10, 20 e 30\%; e duas formas de arraçoamento: ração seca e ração úmida) e quatro repetições por tratamento. A unidade experimental foi constituída por dois animais (um macho castrado e uma fêmea).

Os leitões foram alojados em um galpão aberto, construído em alvenaria, com pé direito com altura de 2,5 metros, cobertura com telhas de barro e piso compacto de cimento de rugosidade média com declividade em torno de 3\%. Cada unidade experimental foi alojada em uma baia medindo 1,00 $\mathrm{m}$ de largura por 2,00 m de comprimento, equipada com comedouro de cimento e um bebedouro tipo chupeta, instalados em extremidades opostas.

Durante todo o período experimental, os dados de temperatura e umidade relativa do ar foram coletados no início da manhã e no final da tarde. As temperaturas foram registradas por termômetros de máxima e mínima e a umidade relativa do ar por meio de termohigrômetro. Os dados de precipitação pluviométrica foram obtidos junto ao Setor de Meteorologia Agrícola do Departamento de Engenharia Agrícola (DENA/CCA/UFC), situado a 300 metros do galpão experimental.

Para a formulação das rações experimentais (Tabela 1) foram consideradas as exigências nutricionais recomendadas por ROSTAGNO et al. (2005) para leitões de 15 à $30 \mathrm{~kg}$ de peso vivo. As rações experimentais foram formuladas para serem isoproteicas, isocalóricas, isolisínicas, isocálcicas e isofosfóricas.

Os alimentos foram submetidos à análise bromatológica no Laboratório de Nutrição Animal (LANA) do Departamento de Zootecnia da 
Universidade Federal do Ceará, e foram obtidos 89,49\% de matéria seca e $11,46 \%$ de proteína bruta para o farelo de arroz integral; $88,47 \%$ de matéria seca e $8,78 \%$ proteína bruta para o milho grão; e $88,70 \%$ de matéria seca e 47,10\% de proteína bruta para o farelo de soja. Os valores de cálcio, fósforo, lisina, metionina, metionina+cistina, fibra bruta, FDN, FDA, sódio e gordura foram baseados nas tabelas de ROSTAGNO et al. (2005) e foram corrigidos de acordo com a matéria seca encontrada.

$\mathrm{O}$ arraçoamento foi feito quatro vezes ao dia (8:00, 11:00, 14:00 e 17:00h) com rações secas e rações umedecidas. $\mathrm{O}$ fornecimento de água foi à vontade em bebedouros automáticos tipo chupeta. Os tratamentos correspondentes às rações com inclusão de água (rações úmidas) obedeceram à relação de mistura de duas partes de ração para uma parte de água (2:1), sendo as quantidades pesadas previamente a cada manejo e umedecidas trinta minutos antes do fornecimento.

Diariamente, antes de oferecer as rações, as sobras e os desperdícios eram recolhidos e pesados para não serem computados como consumo diário de ração, sendo que as sobras e os desperdícios das rações dos tratamentos com inclusão de água (rações úmidas) foram submetidos à pré-secagem, em estufa com circulação de ar forçada a $55^{\circ} \mathrm{C}$ durante 72 horas e posteriormente pesadas.

TABELA 1. Composição percentual, nutricional e custos das rações experimentais na fase inicial II (43 a 67 dias de idade)

\begin{tabular}{|c|c|c|c|c|}
\hline \multirow{2}{*}{ Ingredientes (\%) } & \multicolumn{4}{|c|}{ Níveis de inclusão de Farelo de Arroz Integral (\%) } \\
\hline & 0 & 10 & 20 & 30 \\
\hline Milho grão & 65,55 & 55,96 & 46,31 & 36,71 \\
\hline Farelo de soja & 24,84 & 24,14 & 23,46 & 22,76 \\
\hline Farelo de arroz integral & 0,00 & 10,00 & 20,00 & 30,00 \\
\hline Leite em pó desnatado & 3,00 & 3,00 & 3,00 & 3,00 \\
\hline Açúcar & 3,00 & 3,00 & 3,00 & 3,00 \\
\hline Fosfato monobicálcico & 1,42 & 1,30 & 1,18 & 1,06 \\
\hline Calcário calcítico & 0,84 & 0,88 & 0,96 & 1,01 \\
\hline Suplemento vitamínico-mineral ${ }^{1}$ & 0,40 & 0,40 & 0,40 & 0,40 \\
\hline Sal comum & 0,38 & 0,38 & 0,38 & 0,38 \\
\hline L-lisina $\mathrm{HCl}$ & 0,24 & 0,22 & 0,19 & 0,17 \\
\hline DL-metionina & 0,02 & 0,02 & 0,01 & 0,00 \\
\hline Óleo Vegetal & 0,31 & 0,70 & 1,11 & 1,51 \\
\hline Total $(\mathrm{Kg})$ & 100,00 & 100,00 & 100,00 & 100,00 \\
\hline Custo do kg da ração (R\$) & 1,02 & 1,00 & 0,97 & 0,95 \\
\hline \multicolumn{5}{|l|}{ *Níveis nutricionais calculados } \\
\hline Energia metabolizável (kcal/kg) & 3.230 & 3.230 & 3.230 & 3.230 \\
\hline Proteína bruta $(\%)$ & 18,13 & 18,13 & 18,13 & 18,13 \\
\hline Fibra bruta $(\%)$ & 2,48 & 3,06 & 3,65 & 4,23 \\
\hline FDN $(\%)$ & 11,14 & 11,90 & 12,63 & 13,39 \\
\hline $\operatorname{FDA}(\%)$ & 4,35 & 4,57 & 4,79 & 5,00 \\
\hline Fósforo total (\%) & 0,58 & 0,69 & 0,80 & 0,92 \\
\hline Fósforo disponível (\%) & 0,40 & 0,40 & 0,40 & 0,40 \\
\hline Cálcio $(\%)$ & 0,72 & 0,72 & 0,72 & 0,73 \\
\hline Lisina $(\%)$ & 1,12 & 1,12 & 1,12 & 1,12 \\
\hline Metionina+Cistina (\%) & 0,62 & 0,62 & 0,62 & 0,62 \\
\hline Gordura $(\%)$ & 2,93 & 4,59 & 6,25 & 7,91 \\
\hline \multicolumn{5}{|c|}{$\begin{array}{l}\text { 'Suplemento Vitamínico e Mineral. Quantidade por Kg do produto: Vitamina A 1.500.000,00 UI; Vitamina D3 450.000,00 UI; } \\
\text { Vitamina E 7.500,00 mg; Vitamina K3 1.500,00; Tiamina (Vitamina B1) 250,00 mg; Riboflavina (Vitamina B2) 1.300,00 mg; } \\
\text { Piridoxina (Vitamina B6) 375,00 mg; Vitamina B12 5.000,00 mg; Niacina 7.500,00 mg; Pantotenato de Cálcio 4.500,00 mg; } \\
\text { Ácido Fólico 150,00 mg; Biotina 22,50 mg; Colina 68,000,00 mg; Ferro 12.500,00 mg; Cobre 5.250,00 mg; Manganês 8.750,00 } \\
\text { mg; Zinco 26.250,00 mg; Iodo 350,00 mg; Selênio 75,00 mg. } \\
\text { *De acordo com a recomendação de ROSTAGNO et al. (2005). }\end{array}$} \\
\hline
\end{tabular}

Os dados referentes ao consumo diário de ração (CDR) e ganho diário de peso (GDP) foram obtidos por pesagens semanais individuais dos animais e de suas respectivas rações, menos os desperdícios. A partir desses dados calculou-se a conversão alimentar (CA). 
Para verificar a viabilidade econômica da utilização do farelo de arroz integral, determinou-se inicialmente o custo das rações (CR) por quilograma de peso vivo ganho (Yi), segundo a equação proposta por BELLAVER et al. (1985): Yi = (Qi x Pi) / Gi, onde Yi = custo da ração por quilograma de peso vivo ganho no i-ésimo tratamento; $\mathrm{Pi}=$ preço por quilograma da ração utilizada no i-ésimo tratamento; Qi = quantidade de ração consumida no i-ésimo tratamento e $\mathrm{Gi}=$ ganho de peso do i-ésimo tratamento. Em seguida, foram calculados o Índice de Eficiência Econômica (IEE) e o Índice de Custo (IC) propostos por FIALHO et al. (1992): IEE $=($ MCei $/$ CTei $)$ x 100 e IC $=($ CTei $/$ MCei) x 100, onde MCei = Menor custo da ração por quilograma ganho, observado entre tratamentos e CTei $=$ Custo do tratamento i considerado.

Os valores (preços $/ \mathrm{kg}$ ) dos ingredientes utilizados na elaboração dos custos foram obtidos na região metropolitana de Fortaleza, no mês de abril de 2009, sendo: milho ( $\mathrm{R} \$ 0,53$ ), farelo de soja ( $\mathrm{R} \$ 1,06)$, farelo de arroz integral $(\mathrm{R} \$ 0,30)$, leite em pó desnatado (R\$ 9,10), açúcar (R\$ 0,90), óleo de soja ( $\mathrm{R} \$ 2,50)$, fosfato mono-bicálcico $(\mathrm{R} \$ 3,00)$, calcário calcítico $(\mathrm{R} \$$ $0,15)$, sal comum ( $\mathrm{R} \$ 0,18)$, L-lisina $\mathrm{HCl}(\mathrm{R} \$ 8,00)$, DL-metionina ( $\mathrm{R} \$ 20,00)$, premix vitamínico-mineral (R\$ 9,38).

As análises estatísticas foram realizadas utilizando-se o software estatístico SAS (2001). Os dados de desempenho zootécnico e viabilidade econômica foram submetidos à análise de variância e as médias comparadas pelo Teste SNK (5\%).

\section{RESULTADOS E DISCUSSÃO}

A temperatura ambiental média no interior do galpão durante o período experimental foi de $27,8^{\circ} \mathrm{C}$, sendo as médias registradas de temperatura máxima e mínima de $30,7^{\circ} \mathrm{C}$ e $25,0^{\circ} \mathrm{C}$, respectivamente. A umidade relativa do ar foi em média $67 \%$. Também foi registrado nesse período uma precipitação pluviométrica de 126,8 mm com 12 dias de precipitação. As temperaturas do ar registradas encontram-se acima da faixa ideal de conforto térmico para leitões desmamados, mantidos em condições de umidade relativa do ar em torno de $67 \%$, que se situa entre $24,0^{\circ} \mathrm{C}$ e $22,0^{\circ} \mathrm{C}$, todavia dentro dos limites de temperatura crítica superior e inferior, $34,0^{\circ} \mathrm{C}$ e $15,0^{\circ} \mathrm{C}$; respectivamente (HANNAS, 1999). Deve-se considerar que a zona de termoneutralidade dos animais está relacionada com um ambiente térmico ideal, onde a diferença entre as temperaturas máximas e mínimas é estreita e, dentro da qual, os animais encontram condições adequadas para expressar suas melhores características produtivas.

As médias do consumo diário de ração (CDR), ganho diário de peso (GPD) e conversão alimentar (CA) dos leitões de 43 a 67 dias de idade, alimentados com rações contendo diferentes níveis de inclusão de farelo de arroz integral estão apresentados na Tabela 2.

TABELA 2 - Desempenho zootécnico dos leitões na fase inicial II (43 aos 67 dias de idade) alimentados com dietas contendo diferentes níveis de inclusão de farelo de arroz integral e formas de arraçoamento

\begin{tabular}{|c|c|c|c|c|c|}
\hline \multirow{2}{*}{ Formas de arraçoamento } & \multicolumn{4}{|c|}{ Níveis de inclusão de FAI $^{1}(\%)$} & \multirow{2}{*}{ Média } \\
\hline & 0 & 10 & 20 & 30 & \\
\hline \multicolumn{6}{|l|}{ Consumo diário de ração } \\
\hline Ração seca & 1,243 & 1,236 & 1,142 & 1,208 & $1,209^{\mathrm{a}}$ \\
\hline Ração úmida & 1,227 & 1,264 & 1,208 & 1,135 & $1,207^{\mathrm{a}}$ \\
\hline Média & 1,235 & 1,250 & 1,175 & 1,172 & \\
\hline $\mathrm{CV}(\%)^{2}$ & & & & & \\
\hline \multicolumn{6}{|l|}{ Ganho diário de peso } \\
\hline Ração seca & 0,696 & 0,694 & 0,627 & 0,699 & $0,679^{\mathrm{a}}$ \\
\hline Ração úmida & 0,648 & 0,709 & 0,670 & 0,649 & $0,669^{\mathrm{a}}$ \\
\hline Média & 0,672 & 0,702 & 0,648 & 0,674 & \\
\hline $\begin{array}{ll}\mathrm{CV}(\%)^{2} & 17,09\end{array}$ & & & & & \\
\hline \multicolumn{6}{|l|}{ Conversão alimentar } \\
\hline Ração seca & 1,785 & 1,776 & 1,820 & 1,730 & $1,777^{\mathrm{a}}$ \\
\hline Ração úmida & 1,905 & 1,783 & 1,823 & 1,759 & $1,818^{\mathrm{a}}$ \\
\hline Média & 1,845 & 1,780 & 1,822 & 1,744 & \\
\hline
\end{tabular}

${ }^{a}$ Médias seguidas de mesma letra na coluna não diferem entre si $(\mathrm{P}>0,05)$ pelo teste $\mathrm{F} ;{ }^{\mathrm{I}} \mathrm{FAI}$ - Farelo de arroz integral; ${ }^{2} \mathrm{CV}-$ Coeficiente de variação. 
Não foi observada interação significativa entre os fatores nível de inclusão de FAI e forma de arraçoamento sobre o consumo diário de ração, ganho diário de peso e conversão alimentar dos leitões. Essas variáveis também não foram influenciadas significativamente pelo nível de inclusão de FAI na ração ou pela forma de arraçoamento.

Alguns aspectos devem ser considerados para o uso de ingredientes fibrosos na alimentação de leitões na fase inicial, visto que o nível de consumo retrata a aceitação do alimento fornecido aos leitões e influencia no ganho de peso.

Rações com maiores teores de fibra diminuem a energia digestível, o que resulta em aumento no consumo para suprir a deficiência energética (RAMONET et al., 1999). Ao contrário disso, o consumo de ração pode diminuir com o aumento da fração fibrosa nas rações em decorrência do aumento da viscosidade da digesta que, por sua vez, pode aumentar o volume ocupado pelo alimento no trato gastrointestinal, mantendo a saciedade física por mais tempo e diminuindo o estímulo do animal em consumir ração e até mesmo diminuir a velocidade de trânsito da digesta (BEDFORD, 2000).

Considerando que o ganho de peso dos animais pode ser diretamente influenciado pela ingestão e o aproveitamento dos nutrientes da ração, criou-se a expectativa de que o aumento de fibra na ração associada à maior inclusão de FAI pudesse prejudicar os resultados de ganho de peso e a conversão alimentar dos leitões, o que não ocorreu. Se a fibra bruta na dieta fosse acima de 7\% (KASS et al., 1980) ou o FDN fosse superior a 15\% (STHALY \& CROMWELL, 1986) possivelmente teria prejudicado o desempenho dos animais.

Vale ressaltar que, para tornar as rações isoenergéticas, à medida que se aumentou a inclusão do FAI, houve a necessidade de incluir óleo de soja, aumentando a porcentagem de gordura da ração. Isso pode ter contribuído para que os resultados de ganho de peso e conversão alimentar dos animais alimentados com maior inclusão do FAI na ração tenham sido semelhantes aos obtidos para o grupo controle. De acordo com SAKOMURA et al. (2004), a adição de gordura na ração beneficia o ganho de peso e a conversão alimentar, devido aos efeitos extracalórico e extrametabólico das gorduras, que consistem, respectivamente, no aumento da disponibilidade dos nutrientes de outros ingredientes da ração e na melhoria da eficiência energética, pelo aumento da energia líquida da ração, em função do menor incremento calórico das gorduras.

Por sua vez, PUPA (2004) relatou que a inclusão de óleo como fonte de energia na ração, além de aumentar o aporte energético, pode ajudar a melhorar a palatabilidade e propiciar uma melhoria na consistência das rações fareladas. Esses efeitos podem ter favorecido a manutenção do consumo dos animais que receberam as rações contendo níveis crescentes de inclusão de FAI, uma vez que esse ingrediente é farináceo e fibroso, características que podem tornar a ração menos densa e pulverulenta, dificultando o consumo.

No geral, pode-se inferir que os leitões aceitaram bem as rações contendo FAI e conseguiram aproveitar os nutrientes da ração, obtendo ganho de peso e conversão alimentar semelhantes aos obtidos com o grupo controle, indicando a viabilidade de inclusão do FAI nessa fase até o nível de $30 \%$. Na literatura não são comuns os relatos do uso de FAI na alimentação de suínos na fase inicial; entretanto, os resultados obtidos na presente pesquisa se assemelham com os obtidos para outras fases de criação que indicaram viabilidade de uso de níveis igual ou superiores ao determinado nessa pesquisa.

De acordo com ARA et al. (1975) e BERTOL et al. (1990), para suínos em crescimento e terminação, o FAI pode ser usado como substituto de parte ou do todo do milho e parte do farelo de soja resultando em uma inclusão de quase $90 \%$. CONCI et al. (1995) trabalharam com a substituição de 20, 40 e $60 \%$ do milho pelo farelo de arroz integral, equivalendo, respectivamente, a 14,28 e $42 \mathrm{~kg}$ na ração de suínos em recria e terminação e concluíram que o FAI pode ser incluído nas rações dos suínos substituindo o milho em até $60 \%$. Já HURTADO NERY et al. (2010) concluíram que a substituição de $100 \%$ do milho por FAI afetou o ganho de peso diário e o peso da carcaça; entretanto, a utilização de até $50 \%$ de FAI em substituição ao milho permite obter desempenho zootécnico e características de carcaça similares aos obtidos com rações baseadas em milho para suínos na fase de terminação. NICOLAIEWSKY et al. (1989) também verificaram que o FAI, quando limitado a 30 ou $40 \%$ da ração, possibilitou a obtenção de resultados semelhantes aos obtidos com rações a base de milho. FIREMAN et al. (2000), trabalhando com suínos em crescimento e terminação, não encontraram efeito sobre a conversão alimentar com a inclusão de FAI até o nível de $50 \%$ com ou sem enzima nas rações. No entanto, CAMPABADAL et al. (1976) observaram redução no ganho de peso diário e conversão alimentar somente a partir do nível de $35 \%$ de FAI na ração de suínos em crescimento e terminação, ao passo que BROOKS \& LUMANTA (1975), trabalhando com suínos na fase de terminação, observaram redução no desempenho a partir do nível de $50 \%$ na ração.

GOMES (2006) indica que suínos jovens 
apresentam possivelmente maiores respostas adaptativas à presença de fibra na ração do que suínos na fase de crescimento e terminação, ou que suínos nessa fase já estariam mais tolerantes à presença de quantidade moderada de fibra na ração.

Para as formas de arraçoamento na fase inicial II (43 a 67 dias de idade), observou-se que não houve efeito significativo $(P>0,05)$ do uso de rações secas e úmidas para as variáveis de ganho diário de peso, consumo diário de ração e conversão alimentar.
Os resultados foram semelhantes aos relatados por SILVA et al. (2002), OLIVEIRA (2005), COSTA et al. (2006), NOGUEIRA Jr. (2007) e RIBEIRO (2009), que não observaram efeito das diferentes formas de arraçoamento (ração seca $\mathrm{x}$ úmida) sobre o desempenho dos leitões no período de creche.

As variáveis de custo da ração por quilograma de peso vivo (CR), índice de eficiência econômica (IEE) e índice de custo da ração (IC) estão apresentadas na Tabela 3.

TABELA 3 - Avaliação econômica dos custos de leitões na fase inicial II (43 aos 67 dias) utilizando diferentes níveis de inclusão de farelo de arroz integral (FAI)

\begin{tabular}{|c|c|c|c|c|c|}
\hline \multirow{2}{*}{ Formas de arraçoamento } & \multicolumn{4}{|c|}{ Níveis de inclusão de FAI $^{1}(\%)$} & \multirow{2}{*}{ Média } \\
\hline & 0 & 10 & 20 & 30 & \\
\hline \multicolumn{6}{|c|}{ Custo da ração por quilograma ganho de peso vivo } \\
\hline Ração seca & 1,82 & 1,78 & 1,77 & 1,64 & $1,75^{\mathrm{a}}$ \\
\hline Ração úmida & 1,94 & 1,78 & 1,77 & 1,67 & $1,79^{\mathrm{a}}$ \\
\hline Média & $1,88^{\mathrm{a}}$ & $1,78^{\mathrm{a}}$ & $1,77^{\mathrm{a}}$ & $1,66 * \mathrm{~b}$ & \\
\hline $\mathrm{CV}(\%)^{2} \quad 5,44$ & & & & & \\
\hline \multicolumn{6}{|c|}{ Índice de eficiência econômica } \\
\hline Ração seca & 91,30 & 93,50 & 94,00 & 101,00 & $95,00^{\mathrm{a}}$ \\
\hline Ração úmida & 85,40 & 93,20 & 94,00 & 99,00 & $93,00^{\mathrm{a}}$ \\
\hline Média & $88,35^{\mathrm{b}}$ & $93,35^{b}$ & $94,00^{b}$ & $100,00^{* \mathrm{a}}$ & \\
\hline $\mathrm{CV}(\%)^{2} \quad 5,48$ & & & & & \\
\hline \multicolumn{6}{|l|}{ Índice de custo } \\
\hline Ração seca & 109,83 & 107,15 & 106,50 & 99,20 & $105,67^{\mathrm{a}}$ \\
\hline Ração úmida & 117,25 & 107,60 & 106,80 & 100,85 & $108,10^{\mathrm{a}}$ \\
\hline Média & $113,54^{\mathrm{a}}$ & $107,37^{\mathrm{a}}$ & $106,63^{\mathrm{a}}$ & $100,00^{\mathrm{b}}$ & \\
\hline $\mathrm{CV}(\%)^{2} \quad 5,44$ & & & & & \\
\hline
\end{tabular}

Não houve interação significativa entre o nível de inclusão de farelo de arroz integral (FAI) e a forma de fornecimento da ração sobre as variáveis econômicas. Também não houve diferença significativa entre fornecer ração seca ou úmida. Entretanto, houve efeito do nível de inclusão de FAI sobre todas as variáveis econômicas avaliadas.

As diferenças significativas entre $o$ desempenho econômico dos leitões alimentados com os diferentes níveis de FAI na ração ficaram restritas entre os resultados obtidos com o nível de $30 \%$ em relação aos demais. O nível de inclusão de $30 \%$ de FAI proporcionou menor custo de ração por quilograma de ganho de peso e índice de custo e maior índice de eficiências econômica em relação aos obtidos com a ração sem inclusão de FAI ou com 10 ou $20 \%$ de FAI.

Considerando que o aumento da inclusão de
FAI nas rações reduziu progressivamente a quantidade de milho e parte do farelo de soja na composição das rações, que o desempenho dos leitões alimentados com $30 \%$ de inclusão do FAI não diferiu significativamente ao obtido para o grupo controle e que esse nível de inclusão apresentou os melhores resultados econômicos, pode-se recomendar a inclusão de até $30 \%$ de FAI em rações para leitões de 43 a 67 dias de idade.

\section{CONCLUSÕES}

Concluiu-se que o farelo de arroz integral (FAI) pode ser utilizado até o nível de $30 \%$ de inclusão nas rações de leitões durante o período inicial II (43 a 67 dias de idade), sem que haja o comprometimento no desempenho zootécnico e 
piora nos índices de viabilidade econômica.

O fornecimento de ração úmida ou seca não teve influência sobre o desempenho dos animais.

\section{REFERÊNCIAS}

ARA, L. V.; OWEN, A. A.; BUITRAGO, J. y PINEDA, G. Determinación del valor nutritivo y del nível optimo de utilización de la harina de arroz en dietas para cerdos. Revista Instituto Colombiano Agropecuario., v.10, p.127-137, 1975.

BEDFORD, M. R. Exogenous enzymes in monogastric nutrition: their current value and future benefits. Animal Feed Science and Technology, v.86, p.1-13, 2000.

BELLAVER, C.; FIALHO, E. T.; PROTAS, J. F. S.; GOMES, P. C. Radícula de malte na alimentação de suínos em crescimento e terminação. Pesquisa Agropecuária Brasileira, v.20, n.8, p.969-74, 1985.

BERTOL, M. T.; NICOLAIEWSKY, S.; PENZ JUNIOR, A. M.; PRATES, E. R. Farelo de arroz integral na alimentação de suínos em crescimento e terminação. Revista da Sociedade Brasileira de Zootecnia, v. 19, n. 2, p. 90-97, 1990.

BROOKS, C. C.; LUMANTA, I. G. Rice bran composition and digestibility by the pig. Journal of Animal Science, vol.41, p.308-317, 1975.

CAMPABADAL, C.; CRESWELL, D.; WALLACE, M. D.; COMBS, G. E. Nutritional value of the rice bran for pigs. Tropical Agriculturist, v.53, n.1, p.141-150p, 1976.

CARVALHO, J. L. V.; BASSINELLO, P. Z. Aproveitamento industrial. In: SANTOS, A. B,; STONE, L. F,; VIEIRA, N. R. A. A cultura do arroz no Brasil. 2. ed. rev. ampl. Santo Antônio de Goiás: Embrapa Arroz e Feijão, 2006. p. 1007-1042.

CONCI, V. A.; MAGALHÃES, R. M.; BENDER, P. E.; MAGGI, L.; OLIVEIRA, M. F. G. de.; COSTA, M. S. S. da.; MARTINS, E. S. Avaliação de subprodutos do arroz na alimentação de suínos. II. O farelo de arroz nas fases de recria e terminação. Pesquisa Agropecuária Gaúcha, v.1, p. 59-67, 1995.

COSTA, E. R.; SILVA, L. P. G.; SILVA, J. H. V.; CARVALHO, L. E.; CARVALHO, M. X. C. de. Desempenho de leitões alimentados com diversas formas físicas de ração. Ciência Animal Brasileira, v.7, n.3, p.241-247, 2006

FIALHO, E. T.; BARBOSA, O.; FERREIRA, A. S.; GOMES, P. C.; GIROTTO, A. F. Utilização da cevada suplementada com óleo de soja para suínos em crescimento e terminação. Pesquisa Agropecuária Brasileira, v. 27, p. 1467-1475, 1992.

FIREMAN, F. A. R.; LÓPEZ, J.; FIREMAN, BARBOSA, A. K.; FIREMAN, A. T. Desempenho e custo de suínos alimentados com dietas contendo 50\% de farelo de arroz integral suplementadas com fitase e/ou celulase. Archivos
Latinoamericanos de Producción Animal, v.8, n.1, p. $18-23,2000$.

GOMES, J. D. F.; BLAZQUEZ, F. J. H.; FUKUSHIMA, R. S.; UTIYAMA, C. E.; OETTING, L. L.; LIMA, G. J. M. M. Efeitos do incremento da fibra em detergente neutro na ração de suínos sobre a histologia de segmentos do trato intestinal. Brazilian Journal of Veterinary Research and Animal Science, v. 43, n. 2, p. 210-219, 2006.

HANNAS, M. I. Aspectos Fisiológicos e a produção de suínos em clima quente. Ambiência e Qualidade na Produção Industrial de Suínos. Piracicaba: FEALQ, 1999, 33p.

HOFFPAUER, D. W. New applications for whole rice bran. Cereal Foods World, v. 50, n. 4, p. 173-174, 2005.

HURTADO NERY, V. L.; SOARES, R. T. R. N; CHIQUIERI, J. Desempenho e características de carcaça de suínos em terminação alimentados com rações contendo subprodutos de arroz. Zootecnia Tropical, v.28, n.1, p.43-49. 2010.

KASS, M. L.; VAN SOEST, P. J.; POND, W. G. 1980. Utilization of dietary fiber from alfalfa by growing swine. I. Apparent digestibility of diet components in specific segments of gastrointestinal tract. Journal of Animal Science, v. 50, p 175, 1980.

LAKKAKULA, N. R.; LIMA, M.H; WALKER, T. Rice bran stabilization and rice bran oil extraction using ohmic heating. Bioresource Technology, v.92, p.157-161, 2004.

LE GOFF, G.; VAN MILGEN, J.; NOBLET, J. Influence of dietary fiber on digestive utilization and rate of passage in growing pigs, finishing pigs and adult sows. Animal Science, v.74, p.503-515, 2002.

LIMA, G. J. M. M.; MARTINS, R. R.; ZANOTTO. Composição química $e$ valores de energia de subprodutos do beneficiamento de arroz. Concórdia, SC: EMBRAPA-CNPSA, 2000. 2p. (Embrapa Suínos e Aves. Comunicado Técnico, 244).

NICOLAIEWISKY, S.; D’AGOSTIN, J.; PENZ JR., A. M.; BERTOL, T. M. Avaliação do farelo de arroz integral como fonte alternativa de fósforo em rações para suínos em crescimento e terminação. Revista da Sociedade Brasileira de Zootecnia, vol.18, n.3, p.260-266, 1989.

NOGUEIRA JR., F. G. Efeito residual da inclusão da raspa integral de mandioca em dietas secas ou úmidas no período de creche sobre o desempenho posterior de suínos. 2007. 98p. Dissertação (Mestrado em Zootecnia) Universidade Federal do Ceará, Fortaleza, 2007. Disponível em: http://www.zootecnia.ufc.br/cariboost_files/dissertacao20 07_francisma_20gomes_20nogueira_20junior.pdf

OLIVEIRA, T. E. S. Efeito da inclusão de raspa integral de mandioca e formas de arraçoamento sobre o desempenho de leitões na fase inicial. 2005. 47f. Dissertação (Mestrado em Zootecnia) - Universidade Federal do Ceará, Fortaleza, 2005. Disponível em: 
http://www.zootecnia.ufc.br/cariboost_files/dissertacao20 05 tania_20elizabeth_20sampaio_20oliveira.pdf

PARRADO, J.; MIRAMONTES, E.; JOVER, M.; GUTIERREZ, J. F.; TERÁN, L. C. DE; BAUTISTA, J. Preparation of a rice bran enzymatic extract with potential use as functional food. Food Chemistry, v.98, p.742-748, 2006.

PUPA, J. M. R. Óleos e gorduras na alimentação de aves e suínos. Revista Eletrônica Nutritime, v.1, n.1, p.69-73, 2004.

RAMONET, Y.; MEUNIER-SALAÜN, M. C.; DOUMAND, J. Y. High fiber diets in pregnant sows: digestive utilization and effects on the behavior of the animals. Journal of Animal Science, Champaign, v. 77, n. 3, p. 591-599, 1999.

RAMOS, L. S. N.; LOPES, J. B.; FIGUEIRÊDO, A. V. de.; FREITAS, A. C.; FARIAS, L. A.; SANTOS, L. S.; SILVA, H. O. Polpa de caju em rações para frangos de corte na fase final: desempenho e características de carcaça. Revista Brasileira de Zootecnia, v.35, n. 3, p. 804-810, 2006.

RIBEIRO, J. C. Utilização do farelo de coco em dietas para leitões na creche. 2009. 85 p. Dissertação (Mestrado em Zootecnia) - Universidade Federal do Ceará, Fortaleza, 2009. Disponível em: http://www.zootecnia.ufc.br/cariboost_files/dissertacao20 09_juliana_20constantino_20ribeiro.pdf
ROSTAGNO, H. S.; ALBINO, L. F. T.; DONZELE, J. L.; GOMES, P. C., OLIVEIRA, R. F., LOPES, D. C., FERREIRA, A. S.; BARRETO, S. L. T. Tabelas Brasileiras para Aves e Suínos: Composição de alimentos e exigências nutricionais. $2^{\mathrm{a}}$. ed. Viçosa, MG: Universidade Federal de Viçosa, 2005. v. 1. 186 p.

SAKOMURA, N. K.; LONGO, F. A.; RABELLO, C. B.; WATANABE, K., PELÍCIA, K. E FREITAS, E.R. Efeito do nível de energia metabolizável da dieta no desempenho e metabolismo energético de frangos de corte. Revista Brasileira de Zootecnia, v.33, p.1758-1767, 2004.

SELLE, P. H.; RAVINDRAN, V.; CALDWELL, A.; BRYDEN, W. L. Phytate and phytase: consequences for protein utilization. Nutrition Research Reviews, v.13, p.255-278, 2000.

SILVA, C. A. da; KRONKA, R. N; THOMAZ, M. C.; KRONKA, S. N.; CARVALHO, L. E. de. Rações úmidas e água de consumo e ração com edulcorante para leitões desmamados aos 21 dias e efeito sobre o desempenho até $90 \mathrm{~kg}$ de peso vivo. Ciência Rural, v. 32, n. 4, p. 681-686, 2002.

STHALY, T. S.; CROMWELL, G. L. Responses to dietary additions of fiber (alfalfa meal) in growing pigs housed in a cold, warm or hot thermal environment. Journal of Animal Science, vol.63, p.1870-1876. 1986.

STATISTICAL ANALYSIS SYSTEM - SAS. System for Microsoft Windows. Release 8.2. Cary, 2001. (CDROM) 